\title{
Azacosterol Hydrochloride
}

National Cancer Institute

\section{Source}

National Cancer Institute. Azacosterol Hydrochloride. NCI Thesaurus. Code C78049.

A hydrochloride salt form of azacosterol, a sterol derivative of cholesterol that acts as a hypocholesteremic. 